\title{
Correction to: Anthropometric characteristics of 65 Polish Smith-Lemli-Opitz patients
}

\author{
A. Różdżyńska-Świątkowska ${ }^{1} \cdot$ E. Ciara ${ }^{2} \cdot$ P. Halat-Wolska ${ }^{2} \cdot$ M. Krajewska-Walasek ${ }^{2,3} \cdot$ A. Jezela-Stanek ${ }^{3}$
}

Published online: 27 May 2021

(c) Institute of Plant Genetics, Polish Academy of Sciences, Poznan 2021

Correction to: Journal of Applied Genetics (2021) https://doi.org/10.1007/s13353-021-00632-5

The original article was published with an error. Author would like to update Fig. 1 and Supplementary Table for clarity.

The original article has been corrected.
Publisher's Note Springer Nature remains neutral with regard to jurisdictional claims in published maps and institutional affiliations.

The original article can be found online at https://doi.org/10.1007/ s13353-021-00632-5.

A. Jezela-Stanek jezela@gmail.com

A. Różdżyńska-Świątkowska a.rozdzynska-swiatkowska@ipczd.pl

1 Anthropology Laboratory, Children's Memorial Health Institute, Warsaw, Poland

2 Department of Medical Genetics, The Children's Memorial Health Institute, Warsaw, Poland

3 Department of Genetics and Clinical Immunology, National Institute of Tuberculosis and Lung Diseases, Warsaw, Poland 